\title{
A realidade da cadeia do trigo no Brasil: o elo produtores/cooperativas
}

\author{
Argemiro Luís Brum ${ }^{1}$ \\ Patrícia Kettenhuber Müller²
}

\begin{abstract}
Resumo: O presente artigo tem como objeto a cadeia produtiva do trigo no Brasil e destaca a realidade econômica de seus principais elos, com ênfase nos elos da produção agrícola e industrial do cereal. Salientase que o artigo traz a atualidade do setor no Brasil, a partir da análise dos resultados de pesquisa de campo realizada com produtores rurais, cooperativas e moinhos de trigo. O estudo da cadeia tritícola brasileira, com seus problemas, oferece uma luz para melhor compreensão das condições que o país possui para não só responder às dúvidas expostas, mas, sobretudo, apontar o caminho seguido pela produção de trigo no Brasil nesse início de século XXI. A triticultura nacional está ameaçada e dificilmente alcançará a auto-suficiência, pois os produtores brasileiros não possuem vantagens comparativas e competitivas suficientes, particularmente em relação aos produtores argentinos. A comercialização do trigo também enfrenta dificuldades, tanto na questão de preços do produto, quanto na qualidade exigida pelos moinhos. A retirada da intervenção estatal na produção nacional de trigo, em 1990/91, que a deixou ao sabor do mercado, alterou completamente o quadro de

${ }^{1}$ Professor e pesquisador do Departamento de Economia e Contabilidade da Unijuí, doutor pela EHESS de Paris/França, coordenador do Projeto. E-mail: argelbrum@ unijui.edu.br

${ }^{2}$ Aluna de graduação do Curso de Economia da Unijui, bolsista do Grupo Pet-Economia. E-mail: patricia.muller@unijui.edu.br
\end{abstract}


competitividade dos produtores e da própria cadeia produtiva. Uma das principais conclusões é de que a cadeia tritícola brasileira não funciona a contento, a eficiência da produção nacional está em xeque e seu futuro, comprometido.

Palavras-chave: trigo, cadeia produtiva, competitividade

\title{
Classificação JEL: D23
}

\begin{abstract}
The present article is about the wheat productive chain in Brazil and focuses on the economic reality of its main connecting links, with emphasis on the links between agricultural and industrial production. Let it be accentuated that the article brings present time accounts of the sector in Brazil, from the result analysis of field research among agricultural producers, producer co-operatives and wheat mills. The study of the Brazilian wheat culture chain, with its problems, offers a broader view to understand the e country's conditions, which would allow us not only to answer the exposed doubts, but over all to shed some light on the main paths traced by Brazil's wheat production in these first years of the XXIst century. The national wheat culture is threatened and will hardly reach self-sufficiency, since Brazilian producers cannot become competitive enough, neither sustain comparative advantages particularly in relation to competitors from Argentina. Wheat commercialization faces equal misfortune, whether related to the product's prices or to the quality demanded by the mills. Since the full withdrawal of state intervention in national wheat production, carried out in 1991/91, wheat production has been regulated merely by market moods, and this completely modified the status of Brazilian producer competitiveness and it's negative aftermath is felt throughout chain itself. Thus, one of the main conclusions is that the Brazilian wheat chain does not function adequately, as the efficiency of the national production is kept in check, and its future, compromized.
\end{abstract}

Keywords: wheat, productive chain, competitiveness

Jel Classification: D23 


\section{Introdução}

A cadeia do trigo pode ser dividida em insumos, produção, moinhos, transformação e distribuição/consumo. Este artigo privilegia um segmento desta cadeia, que é o da produção, composto pelos produtores de trigo e suas cooperativas. O trabalho ganha importância pelo fato de que, no seu total, a cadeia tritícola brasileira movimentava, em 2002 (últimos dados estabelecidos), um total de R $\$ 37$ bilhões (ROSSI e NEVES, 2004). Todavia, o trigo brasileiro continua enfrentando problemas na produção, comercialização e em sua viabilidade econômica. Para muitos, o que precisa ser esclarecido é até que ponto as dificuldades da comercialização do trigo nacional decorrem da facilidade de importação do trigo do exterior (FGV/IPEA, 1998). Para outros, o futuro da triticultura nacional está ameaçado e dificilmente chegaremos à autosuficiência, pois os produtores brasileiros não possuem vantagens comparativas e competitivas suficientes diante de seus rivais argentinos.

A análise desse importante elo da cadeia tritícola brasileira, composto pelos produtores e suas cooperativas, busca oferecer uma luz para uma melhor compreensão das condições que o país tem para não só responder às dúvidas expostas, mas sobretudo apontar o caminho seguido pela produção de trigo no Brasil neste início de século XXI.

\section{Aspectos da produção de trigo no Brasil na ótica da cadeia}

Em 2002, a produção rural foi quantificada por meio da multiplicação da produção de trigo da safra 2001/2002 (2.913.900 toneladas e seu preço médio). Assim, o montante obtido com a comercialização daquela safra foi de R 1,152 bilhão. Considerando que o valor movimentado pelo segmento de insumos agrícolas foi de $\mathrm{R} \$ 1,081$ bilhão naquele ano, o saldo de R 71 milhões foi o resultado da agregação de serviços, mão-de-obra e margem de lucro de um nível para outro. No mesmo nível da produção de trigo encontram-se as importações de trigo-grão, pois a produção nacional não é suficiente para suprir as necessidades internas. Portanto, grande parte do trigo utilizado pelos moinhos é proveniente de outros países. No ano de 2002, as importações de trigo somaram R \$2,634 bilhões. Assim, a produção rural juntamente com as 
importações de trigo em grão, em 2002, movimentou R $\$ 3,79$ bilhões. Paralelamente, em 2002, o governo federal recolheu um montante de aproximadamente $\mathrm{R} \$ 1,8$ bilhão com a tributação dos agentes participantes da cadeia do trigo. Esses tributos (PIS/Pasep; Cofins e CPMF em cascata), recolhidos em 2002, estão distribuídos da seguinte forma entre os "elos" produtivos da cadeia (não estão inclusos aqui os setores de distribuição): insumos agrícolas: US\$ 30,6 milhões (setor de sementes - US\$ 2,5 milhões; corretivos - US\$ 70 mil; defensivos - US\$ 6 milhões; máquinas e implementos - US $\$ 13,5$ milhões; fertilizantes - US $\$ 8,5$ milhões); insumos para moinhos: US $\$ 47,2$ milhões (setor de plásticos flexíveis - US\$ 21 milhões; papelão ondulado - US\$ 640 mil; açúcar - US\$ 17 milhões; sal - US\$ 790 mil; fermento - US\$ 5,5 milhões; oxidantes - US\$ 740 mil; enzimas - US\$ 1,5 milhão); produção rural: US\$ 11 milhões; moinhos: US 181 milhões; indústria de alimentos e rações: US\$ 1,5 bilhão: (setor de massas - USS 76 milhões; panificação - US\$ 66,5 milhões; padarias - US\$ 665 milhões; biscoitos - US\$ 113 milhões; ração animal - US\$ 553 milhões) (ROSSI \& NEVES, 2004).

Esse conjunto de informações comprova a importância relativa da triticultura na economia agrícola brasileira, justificando por si só um aprofundamento quanto à realidade do setor produtivo ligado ao cereal.

\subsection{Impactos da desregulamentação na produção ${ }^{3}$}

A intervenção do governo no mercado do trigo, consolidada no Decreto-Lei $\mathrm{n}^{\circ} 210$, de 1967, resultou em uma total desvinculação do mercado brasileiro em relação ao preço internacional. Para se ter uma idéia do descaso com a paridade internacional, em 1986 o preço internacional era de US\$130,00/tonelada e o preço interno, em nível do produtor no Brasil, era de US\$241,00/tonelada, passando a US\$ 185,00/tonelada em 1987 e 1988. Em vista disso, a desregulamentação do setor e a abertura da economia não poderiam ter deixado de causar um profundo impacto no setor.

No momento da extinção da política oficial para o trigo, o preço CIF

${ }^{3}$ A abordagem deste tópico está pautada nas idéias de COLLE, Célio Alberto. A Cadeia Produtiva do Trigo no Brasil: contribuição para a geração de emprego e renda. IEPE/ UFRGS. Ed. UFRGS : Porto Alegre/RS, 1998. Disponível em: < http://www.ufrgs.br/pgdr/ dissertacoes/ecorural/ mecorural colle n204.pdf > . Acesso em setembro de 2005. 
de importação se encontrava em nível bastante deprimido, pressionado pelos elevados volumes dos estoques mundiais e pelo amplo programa de subsídio às exportações do trigo estadunidense. Em 1991 e 1992, as cotações FOB Argentina chegaram a atingir US\$ 90,00/tonelada. A partir de 1994, o Brasil deixou de adquirir o trigo estadunidense pelo programa de EEP (Programa de Incentivo às Exportações) e a sua referência internacional voltou a se situar aos níveis de US\$159,00/tonelada FOB Golfo e US\$120,00 a US\$ 135,00 FOB Argentina.

Mesmo com a extinção da intervenção estatal, os preços mínimos no Brasil ainda se conservaram elevados em relação aos preços de mercado, passando o governo a adotar o sistema de Prêmio de Escoamento de Produto (PEP), além de a Conab ter permanecido ativa nas compras do cereal, com os níveis médios de sustentação fixados em US\$94,52/tonelada, enquanto os preços internacionais mantinham-se ao redor de US\$ 140,00/tonelada. O produto nacional ainda se direcionava para as mãos do governo, pois os moinhos tinham melhores condições na importação.

No período de 1995 até final de 1996, os preços internacionais se elevaram a níveis recordes devido ao desequilíbrio entre oferta e demanda, e à queda no nível dos estoques mundiais, atingindo patamares de US\$ 190,00 a US\$ 220,00/tonelada, elevando os preços de importação e produzindo uma situação de convergência entre os preços externos e internos. Pela primeira vez desde a extinção do monopólio estatal de compra, a Conab deixou de ser a opção de mercado do trigo, processando-se negociações diretas entre os moinhos e os produtores, como convém a um mercado desregulamentado. Os preços mínimos foram reduzidos para US $\$ 157,00 /$ tonelada, porém, a partir de 1997 com a reversão no cenário mundial e queda das cotações, voltaram a se situar acima dos níveis de paridade de importação. Os estoques de passagem da Conab nas safras 1996/97 e 1997/98 ficaram em 692.000 toneladas e 507.000 toneladas respectivamente, o que significou $25 \%$ e $30 \%$ da produção nacional do grão, indicando ainda uma forte intervenção estatal na comercialização do produto, operacionalizada por meio do mecanismo PEP, pelo qual o governo subvenciona a diferença entre o preço de mercado (mais baixo) e o preço mínimo (mais elevado) nos leilões de venda do produto.

A queda da produção, após a reforma, era esperada, porquanto o 
governo adquiria o produto a preços artificialmente acima da paridade antes da política de liberalização do mercado do trigo. Entretanto a intensidade da queda foi muito maior do que se poderia supor.

O setor produtor do grão, primeiro elo da cadeia do trigo, deu logo sinais de que esse processo de desregulamentação havia se constituído em um overshooting. A primeira safra de trigo nacional comercializada após a desestatização foi feita em um cenário de preços bastante deprimidos. Os moinhos passaram a se abastecer do trigo importado em razão dos preços relativamente mais baixos, da melhor qualidade e das facilidades de financiamento. Como a reforma da política extinguiu os preços de aquisição e introduziu o trigo na pauta de preços mínimos, devido à defasagem de preços, as primeiras safras, após a desestatização, foram parar nas mãos do governo ou foram vendidas aos moinhos a preços substancialmente mais baixos que os prevalecentes em períodos passados. As conseqüências foram sucessivas quedas de área e de produção. O governo reagiu com uma política de apoio através dos mecanismos tradicionais e criando ainda novos mecanismos, mas não foi capaz de deter a substancial redução da produção nacional.

Paralelamente, um princípio estava sendo questionado: liberdade de mercado para o setor agrícola pressupõe a não internalização de práticas desleais de comércio, e a competitividade pressupõe condições eqüitativas de concorrência entre os parceiros. No entanto, o governo brasileiro reagiu com descaso em relação à internalização de produto proveniente de países que subsidiavam suas produções e exportações. O argumento utilizado para evitar uma aplicação de salvaguardas foi o de que a elevação dos preços do trigo traria impacto sobre a inflação. Esse argumento havia sido utilizado pelo interesse organizado dos moinhos reiterado diversas vezes no passado. Na prática, para favorecer uma redução dos preços do trigo e derivados no mercado interno, o governo brasileiro apoiou fortemente a desregulamentação do setor e a abertura do mercado a qualquer produto importado. Essa medida, além de favorecer o trigo argentino, permitiu a livre entrada do trigo subsidiado diretamente dos EUA e da União Européia, ou através de triangulação via Uruguai e outros países, mesmo havendo a Tarifa Externa Comum no seio do Mercosul.

Tal estratégia colocou em xeque a produção nacional do cereal, le- 
vando a uma forte redução na oferta local pela redução na área plantada e diminuição dos investimentos em tecnologia por parte do produtor. Assim, de uma quase auto-suficiência em 1986/87 (6,5 milhões de toneladas), depois de duas décadas, o país retrocedeu para uma produção média que varia entre 4 e 6 milhões de toneladas, respondendo por cerca de apenas $50 \%$ da demanda interna. Além disso, não existem expectativas de recuperação dessa produção sem que sejam feitas alterações nas condições de mercado e na postura do Estado em relação ao produto.

Neste contexto, sob o ângulo do produtor, pode-se dizer que mesmo sem tempo e condições de estruturar-se para competir com o produto importado, esse passou a enfrentar (como enfrenta até hoje) a total falta de perspectiva de comercialização dos estoques de safras presentes e passadas, que se acumulam nos armazéns. A comercialização era e ainda é muito difícil com a presença de produto importado em condições de juros e prazos concessionais.

Assim, não foi tentada nenhuma medida para sustar o processo do surto de importações, que acarretou a redução de área e produção não esperados. Com a desregulamentação da comercialização e da industrialização do trigo no país, o mercado do trigo nacional desorganizouse, agravado pelo fato de não ter sido adotada medida de salvaguarda que havia sido determinada pelo Congresso Nacional, preocupado que estava com o que poderia acontecer com o cereal diante das grandes mudanças que vinham ocorrendo nas normas da comercialização e industrialização no mercado interno. Tal realidade evidenciou igualmente a total fragilidade da cadeia do trigo brasileira, que jamais agiu como tal em busca da defesa da atividade. Constantes diferenças internas entre os membros da cadeia, onde o mais forte tira proveito do mais fraco, auxiliaram na estagnação da triticultura nacional a partir da retirada do Estado do processo. Essa realidade praticamente não se alterou até 2006, fato que continua comprometendo a triticultura nacional como uma atividade econômica rentável e viável.

Em suma, a excessiva regulamentação do setor criou distorções no mercado, tanto no produtor quanto na indústria. Quando foi retirada, causou efeitos de redução de área e cultivos do cereal. Não se levou à prática a intenção do governo de promover a abertura prevenindo a concorrência desleal do produto importado que, no caso do trigo, era 
ainda mais procedente, tendo em vista o processo de transição do setor de um mercado estatizado para um mercado livre.

Na prática, em meados dos anos de 1990, detectou-se o abandono de 1,8 milhão de hectares, antes ocupados com trigo. Anos depois, em 2005/06, a situação pouco evoluiu, salvo em momentos esporádicos, quando a produção foi estimulada por elevações de preço conjunturais.

Por outro lado, dentre os efeitos diretos de tal realidade e de acordo com estimativas feitas com base no coeficiente técnico do uso do fator trabalho por hectare, da ordem de um emprego por 15 hectares de trigo plantado, estima-se que foram perdidos cerca de 86.300 empregos na triticultura nacional devido à redução de área com a cultura. Além disso, perdeu-se um fator importante de rateio dos custos de máquinas, equipamentos, benfeitorias, terra e outros fatores, com a cultura da soja, no sistema de double cropping. Este rateio permitia reduzir os custos de produção de soja e outras culturas de verão na ordem de $15 \%$. Em outras palavras, o aumento dos custos das culturas de verão plantadas na área abandonada de trigo foi da ordem de $15 \%$.

\subsection{Problemas e desafios}

A partir do quadro pós-desregulamentação exposto, percebe-se que, na cadeia produtiva do trigo o segmento agrícola é o que apresenta maiores dificuldades para viabilizar e ampliar sua produção. Isso se deve, primeiramente, a uma forte retração nas vendas dos produtores, mediante a, retirada da intervenção estatal no setor. Em segundo lugar, porque há pouca organização e representatividade do segmento produtivo nas instâncias políticas de discussões.

Neste sentido, a montante, as unidades produtivas em geral, não se relacionam diretamente com os fabricantes de insumos, salvo no caso dos grandes produtores, que realizam suas compras diretamente na indústria. Uma parte dos produtores se relaciona com cooperativas para desfrutar de vantagens nas compras em comum, beneficiando-se de preços vantajosos, já que essas operam em grandes escalas e com margens mínimas. A atividade a jusante apresenta relações insípidas com os demais elos da cadeia produtiva e um dos motivos pode ser o tipo de matéria-prima produzida. 
Essa matéria-prima, embora seja semelhante ao produto importado, nem sempre oferece melhores preços, e raramente, melhor qualidade e condições de pagamento. Desta maneira, o moageiro prefere adquirir sua matéria-prima no mercado internacional, privilegiando-se das condições oferecidas. Mesmo assim o cultivo de trigo, através de contratos entre a atividade agrícola e indústria moageira, acabou ganhando um novo fôlego, principalmente entre pequenos e médios moinhos, nos primeiros anos do novo século. $\mathrm{O}$ acordo é realizado mediante o adiantamento pelos moinhos de parte dos recursos que seriam pagos na comercialização do trigo. Através deste mecanismo, uma parte dos produtores pode realizar o plantio da safra futura sem as opções dos mecanismos financeiros tradicionais, a exemplo do crédito rural. Dessa maneira, o produtor e a indústria moageira dividem os riscos. A indústria garante parte da matéria-prima necessária para o processamento do ano seguinte e o produtor recebe pagamento antecipado de parte de sua produção.

No que tange à dinâmica de comercialização, a necessidade de determinada matéria-prima na indústria de transformação poderá fazer com que ocorra a ampliação do número de contratos entre os elos na cadeia produtiva. Um dos fatores que poderá tornar estes contratos mais freqüentes é a identificação, por parte da indústria moageira e de transformação, de quais são as exigências em relação à matéria-prima. De fato, com a ampliação do número de produtos na cadeia produtiva do trigo, as indústrias de transformação demandam matéria-prima com determinadas características. Com isso, abre-se espaço para contratos de fornecimento, vinculando a produção diretamente com a agroindústria, aumentando a integração da cadeia produtiva e tornando-a mais competitiva. A possibilidade do cultivo de trigo através de contratos entre produtores e indústria moageira impõe interesses comuns entre dois elos da cadeia produtiva.

Da mesma forma, a indústria de transformação necessitará de matérias-primas específicas, atuando de forma conjunta com os moinhos. Com a diversificação e ampliação de produtos no mercado, o consumidor passa a nortear toda a cadeia produtiva. Ou seja, ao identificar primeiramente o consumidor, suas características, padrões de preferência, tendências de mudanças, formas de organização social e capacidade de interferir sobre a cadeia, a indústria se tornará competitiva e dinâmica no tempo. 
Neste sentido ZYLBERSZTAJN (1995) afirma que a competitividade de uma cadeia pode estar totalmente atrelada à sua capacidade de adaptar-se rapidamente às mudanças dos padrões de preferência dos consumidores. Ele também pressupõe a existência de canais contínuos de negociação dentro das cadeias. Sempre que o ambiente econômico ou social se modifica, as margens são realocadas ou negociadas. Mas isso só é possível com a maturidade da cadeia produtiva, definida por FARINA e ZYLBERSZTAJN (1991) apud ZYLBERSZTAJN (1995), como a forma pela qual cada ator na cadeia produtiva entende o seu consumidor. Conta também a eficiência com a qual pode adaptar-se às novas situações de mercado (ZYLBERSZTAJN Apud COLLE, 1998).

Na cadeia produtiva do trigo no Brasil, este processo ainda é incipiente e seus atores atuam de forma isolada e desarticulada, limitando a competitividade a alguns elos mais concentrados e, conseqüentemente, capitalizados.

\subsection{Evolução e realidade da triticultura Sul Brasileira}

Em sua fase moderna, a triticultura sul-brasileira pode ser dividida em cinco momentos distintos:

$\rightarrow 1968 / 1980$ - sob o amparo do decreto-lei 210 de 1967, acontece grande expansão da área cultivada. No Rio Grande do Sul, a média anual é de 1.469.985 hectares, chegando a atingir o limite não mais repetido de 2.184.899 hectares no ano de 1979. O rendimento médio de grãos é de 802 quilos/hectare, com grandes frustrações nas safras de 1972 (309 quilos/hectare), 1977 (464 quilos/hectare) e 1979 (448 quilos/hectare).

$\rightarrow 1981 / 1985$ - houve decréscimo da área média anual cultivada para 920.711 hectares, sendo a maior delas em 1982 (1.377.422 hectares), estimulada pelo promissor rendimento obtido na safra anterior. $\mathrm{O}$ rendimento médio de grãos é de 861 quilos/hectare, com o mínimo de 383 quilos/ hectare em 1982 e o máximo de 1.225 quilos/hectare na safra de 1981.

$\rightarrow 1986 / 1989$ - é o melhor momento da história da cultura do trigo no Rio Grande do Sul, quando atinge sua maior produção (1.810.710 toneladas) em 1986. A área média cultivada cresce apenas 7,29\% em relação ao período anterior, passando para 987.806 hectares, enquanto a produção aumenta 107,14\%, alcançando média anual de 1.641.176 toneladas. O rendimento evolui para 1.661 quilos/hectare, ficando apenas 186 quilos 
abaixo daquele obtido na Argentina em igual período. Nesse período, o Brasil quase alcançoua sua auto-suficiência na produção de trigo.

$\rightarrow$ 1990/1999 - extinto o monopsônio-monopólio estatal de trigo em 1990, ocorre acentuada queda na área média anual cultivada, situandose em 572.447 hectares. O rendimento de grãos se reduz para 1.427 quilos/hectare, registrando 701 quilos a menos que a média obtida pelos produtores argentinos no período. A produção média anual atinge 759.648 toneladas, refletindo a queda nos preços de garantia e dificuldades no processo de comercialização (JACOBSEN, 2000).

$\rightarrow 2000 / 2005$ - após o recuo na fase anterior, a área plantada aumenta no Estado gaúcho, chegando a 1,085 milhão de hectares em 2004, graças a um incremento importante nos preços externos e internos, em 2002/03, puxados por uma taxa cambial que chegou a quase $\mathrm{R} \$ 4,00$ por dólar em outubro de 2002. A produção vai a 2,16 milhões de toneladas, com um rendimento médio de 2.000 quilos/hectare. Em volume produzido e produtividade, foi o melhor ano na história da triticultura gaúcha. No entanto, por falta justamente de organização na cadeia e políticas adequadas, a produção caiu fortemente em 2005. Nesse ano, a área semeada recua para 930.000 hectares, a produção fica em 1,67 milhão de toneladas, e a produtividade recua para 1.800 quilos/hectare. A tendência para 2006 era ainda mais negativa, pois os preços do produto na safra de 2005 ficaram ao redor de $\mathrm{R} \$ 18,00 /$ saco, enquanto o preço mínimo oficial era de $\mathrm{R} \$ 24,00 /$ saco.

Por outro lado, no Rio Grande do Sul, o trigo apresenta algumas desvantagens em relação ao Paraná. A primeira, em função das condições climáticas, principalmente pela ameaça de geadas tardias. Enquanto no Paraná a colheita do trigo fora antecipada em até dois meses, permitindo que o produto fosse comercializado no centro do país antes da entrada do produto importado, oriundo principalmente da Argentina. Outro aspecto positivo em favor do Paraná é a proximidade com a Região Sudeste, maior centro consumidor e de processamento do país, o que possibilita o escoamento da safra com menores custos de transporte. Assim, o trigo produzido antecipadamente no Paraná torna-se competitivo no mercado brasileiro e é comercializado a preços mais elevados, viabilizando a pequena e média produção.

Diante de todos esses fatores o que se percebe no Rio Grande do Sul é a falta de condições financeiras para adotar tecnologias, onde peque- 
nos e médios produtores estão abandonando a atividade, permanecendo apenas aqueles que apresentam condições de investir no negócio e gerar escala de produção. A julgar pelos dois últimos censos agropecuários realizados pelo IBGE, esses não representarão mais de $10 \%$ da totalidade dos produtores rurais ainda existentes num futuro próximo.

Em 1985, o número de agricultores que cultivavam trigo no Rio Grande do Sul era de 83.245, com área média de 11,44 hectares por produtor. Já em 1995/96 o número de triticultores no Estado caiu para 33.677, com área média colhida de 9,89 hectares. No Rio Grande do Sul, considerando a totalidade das terras que formam o estabelecimento, o Censo 1995/96 identificou que 15.774 produtores de trigo (46,84\% do total) estavam em imóveis de menos de 1 hectare até menos de 20 hectares, e a área média colhida com trigo foi de 3,06 hectares. Em estabelecimentos com menos de 1 hectare até menos de 50 hectares estavam 27.914 dos produtores $(82,89 \%)$, com $37,95 \%$ da área colhida e $33,21 \%$ da produção (1.203 quilos/hectare). A área média colhida de trigo por esse grupo foi de 4,53 hectares. Por sua vez, produtores com imóveis de 50 a menos de 100 hectares representaram 9,79\% do total, colhendo 14,66\% da área (média de 14,82 hectares), e foram responsáveis por $13,53 \%$ da produção (1.268 quilos/hectare). Os demais, com estabelecimentos cuja área é igual ou maior que 100 hectares, que somam 2.465 triticultores (7,32\%), colheram $47,38 \%$ da área com trigo no Estado $(63,99$ hectares por estabelecimento) e $53,26 \%$ da produção (1543 quilos/hectare) (JACOBSEN, 2000).

\subsubsection{O momento atual dos produtores de trigo no Brasil ${ }^{4}$}

A evolução da triticultura no Brasil confirma uma natural concentração das propriedades rurais. Assim, conforme o Quadro 1, quanto ao tamanho das propriedades rurais nos anos 80 , cerca de $14 \%$ dos produtores ainda ocupavam uma área entre 10 e 30 hectares e $38 \%$ possuíam uma área acima de 100 hectares. Em 2005, apenas 4,8\% dos produtores permaneciam com área de 10 a 30 hectares. Enquanto isso, $81 \%$ dos produtores já tinham uma área acima de 100 hectares.

${ }^{4}$ Cf. pesquisa de campo, realizada em 2005, pelos autores junto aos produtores rurais e as cooperativas agrícolas do Rio Grande do Sul e Paraná, dentro do caso de uma pesquisa intitulada "A Competitividade do Trigo Brasileiro Diante da Concorrência Argentina", realizada junto ao DECon e Mestrado em Desenvolvimento da UNIJUI. 
Quadro 1. Tamanho da propriedade rural - 1980 a 2005 (participação percentual dos produtores)

\begin{tabular}{|c|c|c|c|}
\hline Hectares & Anos 80 (\%) & Anos 90 (\%) & Atualmente (\%) \\
\hline $0-10$ & Zero & zero & Zero \\
\hline $10-30$ & 14,3 & 4,8 & 4,8 \\
\hline $30-50$ & 9,5 & 4,8 & 4,8 \\
\hline $50-70$ & 19,0 & 14,3 & 9,5 \\
\hline $70-100$ & 9,5 & 9,5 & zero \\
\hline Acima de 100 & 38,1 & 61,9 & 80,9 \\
\hline Sem resposta & 9,6 & 4,7 & zero \\
\hline
\end{tabular}

Fonte: Pesquisa de campo realizada com os produtores rurais do RS e PR.

Em segundo lugar, quanto ao arrendamento de terras, o Quadro 2 aponta que $33 \%$ dos produtores afirmaram não possuir terras nessas condições nos anos 80 e 14\% arrendavam acima de 100 hectares. Em 2005 a percentagem de produtores que arrendavam acima de 100 hectares sobe para $29 \%$. Ou seja, em 20 anos aproximadamente, dobrou a percentagem de produtores que passaram a arrendar acima de 100 hectares.

Quadro 2. Área de arrendamento - 1980 a 2005 (participação percentual dos produtores)

\begin{tabular}{|c|c|c|c|}
\hline Hectares & Anos 80 (\%) & Anos 90 (\%) & Atualmente (\%) \\
\hline $0-10$ & 19,0 & Zero & 9,5 \\
\hline $10-30$ & zero & 19,0 & 4,8 \\
\hline $30-50$ & 9,5 & 4,8 & 9,5 \\
\hline $50-70$ & 23,8 & 19,0 & 14,3 \\
\hline $70-100$ & zero & 9,5 & 4,8 \\
\hline Acima de 100 & 14,3 & 19,0 & 28,6 \\
\hline Sem resposta & 33,4 & 28,7 & 28,5 \\
\hline
\end{tabular}

Fonte: Pesquisa de campo realizada com os produtores rurais do RS e PR

Quanto à área plantada com trigo, conforme o Quadro 3, entre própria e arrendada $33,3 \%$ dos produtores semeavam entre 10 e 30 hectares nos anos 80 e outros 33,3\% semeavam entre 70 e 100 hectares, além dos estágios intermediários. Já atualmente, $71,3 \%$ dos produtores se situam com plantio acima de 100 hectares. 
Em 2005, 38\% dos produtores de trigo indicavam plantá-lo em áreas próprias com mais de 100 hectares e $33 \%$ apontavam arrendar área acima de 100 hectares para o plantio do cereal. No outro extremo, apenas $9,5 \%$ plantavam em até 10 hectares de terra própria. O mesmo percentual vale para os produtores que arrendam até 10 hectares para o plantio do trigo.

Quadro 3. Comparativo de área plantada de trigo, própria e arrendada 1980 a 2005 (participação percentual dos produtores)

\begin{tabular}{|c|c|c|c|c|c|c|}
\hline \multirow{2}{*}{ Hectares } & \multicolumn{2}{|c|}{ Anos 80 (\%) } & \multicolumn{2}{c|}{ Anos 90 (\%) } & \multicolumn{2}{c|}{ Atualmente (\%) } \\
\cline { 2 - 7 } & Própria & Arrendada & Própria & Arrendada & Própria & Arrendada \\
\hline $0-10$ & 9,5 & 14,3 & 9,5 & 14,3 & 9,5 & 9,5 \\
\hline $10-30$ & 23,8 & 9,5 & zero & 4,8 & zero & 9,5 \\
\hline $30-50$ & 9,5 & 9,5 & 23,8 & 9,5 & 9,5 & 14,3 \\
\hline $50-70$ & 14,3 & 14,3 & 14,3 & 4,8 & 14,3 & 0 \\
\hline $70-100$ & 23,8 & 9,5 & 9,5 & 4,8 & 14,3 & 4,8 \\
\hline Acima de 100 & zero & 14,3 & 33,3 & 33,3 & 38,0 & 33,3 \\
\hline Sem resposta & 42,9 & 28,6 & 9,6 & 28,5 & 14,4 & 28,6 \\
\hline
\end{tabular}

Fonte: Pesquisa de campo realizada com os produtores rurais do RS e PR

Quanto à produtividade média (em sacos por hectare), nota-se que houve uma melhoria relativa da mesma (Quadro 4). Nos anos 80, 33\% dos produtores indicavam que tinham uma produtividade entre 10 e 30 sacos. Outros $47 \%$ conseguiam entre 30 e 50 sacos por hectare, sendo que somente $4,8 \%$ ficavam entre 50 e 70 sacos. Atualmente, apenas $9,5 \%$ dos produtores estão na faixa de produtividade entre 10 e 30 sacos por hectare. O mesmo percentual é encontrado na faixa de 50 e 70 sacos por hectare. A grande maioria (76\%) se mantém com uma produtividade média entre 30 e 50 sacos.

O preço médio recebido pelos produtores de trigo, nos anos 80 , foi de US\$11,07/saco. Isso representa, com base na produtividade média detectada, um ganho bruto médio ponderado de US\$351,59 por hectare. Já nos anos 90 o preço médio ficou em US\$7,88/saco, fato que levou a renda bruta média ponderada para US\$315,20. Enfim, atualmente (safra 2005), o preço médio foi de US\$ 7,97/saco. Isso representa uma renda bruta ponderada ao redor de US $\$ 302,86$ por hectare para a grande maioria dos produtores. 
Quadro 4. Produtividade média - 1980 a 2005

(participação percentual dos produtores)

\begin{tabular}{|c|c|c|c|}
\hline Sacos/hectares & Anos 80 (\%) & Anos 90 (\%) & Atualmente (\%) \\
\hline $0-10$ & zero & zero & zero \\
\hline $10-30$ & 33,3 & zero & 9,5 \\
\hline $30-50$ & 47,6 & 90,5 & 76,0 \\
\hline $50-70$ & 4,8 & 4,8 & 9,5 \\
\hline $70-100$ & zero & zero & zero \\
\hline Acima de 100 & zero & zero & zero \\
\hline Não Respondeu & 14,3 & 4,7 & 5,0 \\
\hline
\end{tabular}

Fonte: Pesquisa de campo realizada com os produtores rurais do RS e PR

A renda bruta total com o trigo é muito variável. Nos anos 80 a maior parte dos produtores $(24 \%)$ indicou uma renda bruta entre 1.001 e 2.000 sacos, enquanto $14 \%$ ficaram entre 301 e 500 sacos e outros $14 \%$ entre 501 e 700 sacos de renda bruta. Atualmente, $33 \%$ indicaram uma renda bruta acima de 2.000 sacos/hectare e o restante diluído nas demais classificações (Quadro 5).

Quadro 5. Renda bruta total com trigo - 1980 a 2005 (participação percentual dos produtores)

\begin{tabular}{|c|c|c|c|}
\hline Sacos & Anos 80 (\%) & Anos 90 (\%) & Atualmente (\%) \\
\hline Menos de 100 & 9,5 & 4,8 & 9,5 \\
\hline 101 a 300 & 4,8 & 9,5 & 14,3 \\
\hline 301 a 500 & 14,3 & 19,0 & 14,3 \\
\hline 501 a 700 & 14,3 & 9,5 & 14,3 \\
\hline 701 a 1000 & 9,5 & 14,3 & 4,8 \\
\hline 1001 a 2000 & 23,8 & 19,0 & 4,8 \\
\hline Acima de 2000 & 4,8 & 14,3 & 33,3 \\
\hline Sem resposta & 19,0 & 9,6 & 4,7 \\
\hline
\end{tabular}

Fonte: Pesquisa de campo realizada com os produtores rurais do RS e PR

O custo variável da produção de trigo (Quadro 6), nos anos 80, girava entre 11 e 20 sacos por hectare, havendo $24 \%$ dos produtores registrando um custo entre 11 e 15 sacos e $33 \%$ indicando um custo entre 16 e 20 sacos. Outros $14 \%$ registravam um custo acima de 25 sacos por hectare. Nos anos $90,38 \%$ dos produtores apontavam custo entre 21 e 25 sacos e $33 \%$ acima de 25 sacos. Atualmente (2005), 86\% dos produtores indicam que seu custo é superior a 25 sacos por hectare. Ou seja, em 25 anos o custo de produção aumentou consideravelmente para a grande maioria dos produtores. 
Quadro 6. Custo variável de produção com trigo - 1980 a 2005 (participação percentual dos produtores)

\begin{tabular}{|c|c|c|c|}
\hline Sacos/hectare & Anos $\mathbf{8 0}(\%)$ & Anos $\mathbf{9 0}(\%)$ & Atualmente (\%) \\
\hline 01 a 05 & zero & zero & zero \\
\hline 06 a 10 & zero & zero & zero \\
\hline 11 a 15 & 23,8 & 9,5 & zero \\
\hline 16 a 20 & 33,3 & 9,5 & 4,8 \\
\hline 21 a 25 & 4,8 & 38,0 & 4,8 \\
\hline Mais de 25 & 14,3 & 33,3 & 85,7 \\
\hline Sem resposta & 23,8 & 9,7 & 4,7 \\
\hline
\end{tabular}

Fonte: Pesquisa de campo realizada com os produtores rurais do RS e PR

A sobra total em sacos de trigo nos anos 80 demonstrou que $19 \%$ dos produtores conseguiam entre 101 e 300 sacos. Nas demais faixas o número de produtores ficou em 9,5\%. Nos anos 90, 24\% dos produtores indicaram ter obtido uma sobra abaixo de 50 sacos, $19 \%$ indicaram uma sobra entre 701 e 1.000 sacos e $14 \%$ entre 101 e 300 sacos. Enfim, atualmente $43 \%$ apontam uma sobra abaixo de 50 sacos e $24 \%$ uma sobra entre 101 e 300 sacos (ver Quadro 7). Ou seja, o aumento nos custos não foi acompanhado pela melhoria dos preços e tampouco pela produtividade média, fato que levou a uma solução drástica nos ganhos finais.

Quadro 7. Sobra total em sacos de trigo - 1980 a 2005 (participação percentual dos produtores)

\begin{tabular}{|c|c|c|c|}
\hline Sacos & Anos 80 (\%) & Anos 90 (\%) & Atualmente (\%) \\
\hline Menos de 50 & 9,5 & 23,8 & 42,9 \\
\hline 51 a 100 & 9,5 & 4,8 & zero \\
\hline 101 a 300 & 19,0 & 14,3 & 23,8 \\
\hline 501 a 701 & 9,5 & 9,5 & zero \\
\hline 701 a 1000 & 9,5 & 19,0 & 4,8 \\
\hline 1001 a 2000 & 9,5 & 9,5 & 9,5 \\
\hline Acima de 2000 & 9,5 & 4,8 & 4,8 \\
\hline Sem resposta & 24,0 & 14,3 & 14,2 \\
\hline
\end{tabular}

Fonte: Pesquisa de campo realizada com os produtores rurais do RS e PR

Neste sentido, conforme o Quadro 8, o trigo representava, na renda da propriedade rural, nos anos 80 , para $33 \%$ dos produtores, algo entre 50 e $59 \%$ da renda. Para outros $24 \%$, no máximo até $9 \%$ da renda. Nos 
anos 90, 29\% dos produtores já indicavam que o trigo representava apenas entre 20 e $29 \%$ da renda. Atualmente, $57 \%$ dos produtores apontam que o cereal representa até $9 \%$ da renda da propriedade. Outros $29 \%$ permanecem indicando que o trigo representa entre 20 e $29 \%$ da renda e $14 \%$ indicam que o cereal contribui entre 10 e $19 \%$ da renda.

Quadro 8. Valores que o trigo representava na renda da propriedade rural 1980 a 2005 (participação percentual dos produtores)

\begin{tabular}{|c|c|c|c|}
\hline Renda & Anos 80 (\%) & Anos 90 (\%) & Atualmente (\%) \\
\hline $50-59 \%$ & 33,3 & 23,8 & zero \\
\hline $40-49 \%$ & 14,3 & zero & zero \\
\hline $30-39 \%$ & 9,5 & 19,0 & zero \\
\hline $20-29 \%$ & zero & 28,6 & 28,6 \\
\hline $10-19 \%$ & zero & 4,8 & 14,3 \\
\hline $0-9 \%$ & 23,8 & 19,0 & 57,1 \\
\hline Sem resposta & 19,1 & 4,8 & zero \\
\hline
\end{tabular}

Fonte: Pesquisa de campo realizada com os produtores rurais do RS e PR

A grande maioria dos produtores (90\%) apontou fazer uso de financiamento bancário para o plantio do trigo (Quadro 9). Nos anos 80, $19 \%$ dos produtores financiavam entre 100 e 300 hectares de planta. Atualmente, $19 \%$ indicaram financiar entre 31 e 50 hectares, $14 \%$ entre 101 e 300 hectares e outros $14 \%$ entre 301 e 500 hectares.

Quadro 9. Faixa de financiamento por hectare de planta - 1980 a 2005 (participação percentual dos produtores)

\begin{tabular}{|c|c|c|c|}
\hline Hectares & Anos 80 (\%) & Anos 90 (\%) & Atualmente (\%) \\
\hline $0-10$ & zero & zero & 4,8 \\
\hline $11-30$ & 9,5 & 4,8 & 4,8 \\
\hline $31-50$ & 14,3 & 19,0 & 19,0 \\
\hline $51-100$ & 4,8 & 19,0 & 9,5 \\
\hline $101-300$ & 19,0 & 14,3 & 14,3 \\
\hline $301-500$ & 4,8 & zero & 14,3 \\
\hline $501-700$ & 9,5 & 14,3 & 9,5 \\
\hline $701-1000$ & zero & zero & 4,8 \\
\hline Sem resposta & 38,1 & 28,6 & 19,0 \\
\hline
\end{tabular}

Fonte: Pesquisa de campo realizada com os produtores rurais do RS e PR 
Apesar desta realidade não tão propícia ao trigo, 95\% dos produtores informaram que ainda plantavam trigo em 2005. Instados a responder por que plantavam trigo nos anos 80 e porque continuam a plantar atualmente, obtiveram-se as seguintes respostas: ${ }^{5}$

"O plantio nos anos 80 se deu basicamente em função do apoio do governo à cultura, através do preço mínimo, de crédito facilitado e da compra estatal. Além disso, o custo de produção ainda era reduzido e, diante da falta de opção para o inverno, a cultura compensava. Paralelamente, se aproveitava o plantio do trigo para exercer uma rotação de culturas, diluindo os custos fixos da safra de verão.

Quanto a continuar plantando trigo nos dias de hoje, apesar dos baixos preços, da concorrência Argentina, da falta de apoio do governo federal e dos altos custos, a principal motivação vem da necessidade de rotação de culturas e da cobertura de solo durante o inverno. Além disso, pesa ainda o fato da atividade continuar diluindo parcialmente os custos fixos para a safra de verão. Raros foram os produtores que indicaram a esperança de obter uma boa safra para conseguir um complemento de renda no ano.

Quanto àqueles que pararam de plantar ou diminuíram a área plantada, os motivos principais que os levaram a esta atitude são dois: a falta de uma política oficial, apoiada em preços mínimos viáveis; e os baixos preços de mercado associados aos altos custos de produção".

Quanto às cooperativas gaúchas e paranaenses, entre os anos 80 e os anos 2000 todas registraram aumento na sua capacidade total de armazenagem. A maioria aumentou tal capacidade entre 80 e $100 \%$, havendo casos extremos de aumento que superou os $300 \%$. No entanto, esse aumento na capacidade total de armazenagem não se deveu especificamente ao trigo. Isto porque $75 \%$ das cooperativas entrevistadas nos Estados do Rio grande do Sul e Paraná acusaram uma redução de até $50 \%$ no volume armazenado em trigo entre os anos 80 e 2005 . Isto não se deve à redução no número de associados já que em $50 \%$ delas houve um aumento neste número, sendo que em alguns casos se constata quase uma duplicação do mesmo no período considerado. Nas

${ }^{5}$ Respostas obtidas a partir de pesquisa de campo aplicada pelos autores. 
demais, a redução constatada não é expressiva. Quanto aos produtores de trigo associados, o número dos mesmos no total de associados na cooperativa recua fortemente em 25 anos. Nos anos 80, a grande maioria das cooperativas indicava que entre 70 e $90 \%$ de seus associados produziam trigo. Em 2005 as cooperativas indicam que apenas entre 40 e $50 \%$ de seus associados continuam produtores de trigo, havendo casos em que este número recua para tão somente $10 \%$.

Quadro 10. Categoria de produtores associados nas cooperativas agrícolas 1980 a 2005 (participação percentual dos produtores)

\begin{tabular}{|c|c|c|c|}
\hline Hectares & Anos 80 (\%) & Anos 90 (\%) & Atualmente (\%) \\
\hline $11-30$ & 44,4 & 55,5 & 44,4 \\
\hline $31-50$ & 11,1 & 11,1 & zero \\
\hline $51-100$ & 11,1 & 11,1 & 22,2 \\
\hline Sem resposta & 33,4 & 22,3 & 33,4 \\
\hline
\end{tabular}

Fonte: Pesquisa de campo realizada com as cooperativas do RS e PR

Quadro 11. Produtividade média de trigo dos produtores associados 1980 a 2005 (participação percentual dos produtores)

\begin{tabular}{|c|c|c|c|}
\hline Quilos/hectare & Anos 80 (\%) & Anos 90 (\%) & Atualmente (\%) \\
\hline $801-1200$ & 22,2 & zero & zero \\
\hline $1201-1500$ & 55,5 & 22,2 & zero \\
\hline $1501-1800$ & zero & zero & 22,2 \\
\hline $1801-2000$ & zero & 66,7 & 11,1 \\
\hline $2001-2300$ & 11,1 & zero & 33,3 \\
\hline Acima de 2300 & zero & 11,1 & 33,3 \\
\hline Sem resposta & 11,2 & zero & 0,1 \\
\hline
\end{tabular}

Fonte: Pesquisa de campo realizada com as cooperativas do RS e PR

Nota-se igualmente que os produtores associados que continuaram a produzir trigo são aqueles concentrados na faixa de 11 a 30 hectares ( $44 \%$ nos anos $80,55 \%$ nos anos 90 e $44 \%$ atualmente). Todavia, em 2005 vale registrar que $22 \%$ dos mesmos se encontravam na faixa de 51 a 100 hectares. No que tange à produtividade dos produtores associados às cooperativas, nos anos $8055 \%$ alcançavam entre 1.201 e 1.500 quilos por hectare, outros $22 \%$ entre 801 e 1.200 quilos por hectare e $11 \%$ entre 2.001 e 2.300 quilos por hectare. Já em 2005 o desempenho me- 
lhora claramente com $33 \%$ indicando uma produtividade média acima de 2.300 quilos por hectare, outros $33 \%$ uma produtividade entre 2.001 e 2.300 quilos por hectare, $11 \%$ entre 1.801 e 2.000 quilos por hectare e $22 \%$ entre 1.501 e 1.800 quilos por hectare. Vale salientar que, nos anos 90, 67\% dos produtores associados às cooperativas obtinham uma produtividade média entre 1.801 e 2.000 quilos por hectare.

O preço médio obtido pelos produtores associados girava entre US\$ 7,00 e US $\$ 9,00$ por saco de 60 quilos. Atualmente (anos 2000) o preço médio recebido pelos produtores se encontra em US\$ 7,60 por saco no Rio Grande do Sul e US\$ 9,19 por saco no Paraná.

O trigo no período considerado representou relativamente pouco no faturamento global das cooperativas. Nos anos 80, o mesmo esteve ao redor de $20 \%$, conforme os dados pesquisados. Nos anos 90 esta participação caiu para $15 \%$ e atualmente essa participação varia entre $5 \%$ e $15 \%$.

Interessante se faz observar, diante do quadro exposto, que nos anos 80 apenas $22 \%$ das cooperativas possuíam indústria de moagem de trigo. Este número cresce para $33 \%$ nos anos 90, chegando a $55 \%$ em 2005. Ou seja, os produtores reduzem sua participação relativa na produção de trigo, o cereal perde espaço no faturamento da cooperativa, porém contraditoriamente as mesmas aumentam significativamente suas capacidades de moagem.

No que diz respeito à comercialização de trigo, nos anos 80 a mesma era realizada via Banco do Brasil, através de compras estatais. A partir de 1990 a comercialização de trigo passou a ser livre e as cooperativas passaram a comercializá-lo no mercado diretamente. As cooperativas comprando dos produtores no sistema "balcão" (compra direta de qualquer volume com o preço sendo estabelecido em função da qualidade do produto) e no sistema de lotes. Os mecanismos de EGF e AGF igualmente são utilizados, embora em menor intensidade após a retirada do Estado das compras de trigo. O produto entre indústrias passou igualmente a ser vendido no mercado livre, sobretudo através de lotes. Atualmente, as cooperativas destinam parte de seu trigo a seus moinhos (aquelas que possuem parque de moagem), parte para as indústrias moageiras privadas, às vezes certa quantidade para o governo, graças aos leilões PEP (Programa de Escoamento de Produto) e outros mecanismos, e raramente exportam o cereal. 
Segundo as cooperativas, as três maiores dificuldades que seus associados encontram para comercializar o trigo são: forte instabilidade do mercado, com preços geralmente muito baixos; dificuldades de enquadrar o produto ofertado aos padrões exigidos pela indústria, em termos qualitativos; importações constantes sem uma política oficial definida para o produto.

A comercialização do trigo entre as cooperativas e moinhos igualmente enfrenta dificuldades. A primeira delas está na instabilidade do mercado, com baixa liquidez na medida em que os moinhos priorizam pouco a compra do trigo nacional. Isto se deve a qualidade e padronização do produto nacional, aos prazos de pagamento e ao câmbio. Tal realidade gera uma baixa rentabilidade, pois os custos de estocagem e de frete penalizam em demasia as cooperativas, diante de preços geralmente baixos pagos pelos moinhos. Na prática, existe um oligopólio dos grandes moinhos no Brasil, os quais ditam as condições de comercialização a cada safra. Os moinhos menores, em muitos casos, acabam não sendo mais uma solução comercial, pois enfrentam uma situação de inadimplência.

Enfim, as cooperativas destacam as principais diferenças entre a comercialização dos anos 80 e a realizada atualmente. Nos anos 80 , o processo era fácil e tranqüilo porque o Estado comprava todo o produto com subsídios. Os preços eram definidos antecipadamente e portanto o mercado era garantido. Hoje, o mercado é livre, a competição é acirrada e as cooperativas brasileiras enfrentam uma forte concorrência do trigo externo, principalmente do produto oriundo da Argentina. Além disso, há problemas com a qualidade do trigo nacional, devido ao clima muito instável, e à própria exigência dos moinhos em relação ao produto desejado. Em síntese, as exigências de competitividade cresceram significativamente e nem todas as cooperativas conseguem acompanhar o processo.

\section{Considerações finais}

A cadeia produtiva do trigo no Brasil deve estruturar-se e articular-se a partir do consumidor no sentido de aumentar a competitividade em todos os seus elos. Com a exigência por determinadas matérias-primas, de características específicas, a pesquisa passa a ter papel fundamental na oferta de materiais genéticos ao setor primário. Assim sendo, o segmento 
agrícola poderá aumentar o percentual de produto competitivo no mercado brasileiro, gerando renda e emprego não só na atividade "trigo em grão”, mas também em outros elos da cadeia produtiva. Todavia, buscar mecanismos que induzam ao aumento da área cultivada com trigo no Brasil não é tarefa fácil no momento em que ocorrem a integração dos mercados intra e interblocos e a formação de áreas de livre comércio. Neste contexto, com relação ao trigo brasileiro, pode-se fazer dois questionamentos. Deve-se deixar os países, que apresentam (aparentemente) vantagens competitivas, produzir o cereal ou, então, deve-se incentivar a adoção de tecnologias e adotar um modelo de profissionalização da agricultura brasileira com o objetivo da eficiência técnica e econômica?

Por enquanto o país tem se voltado particularmente para a primeira opção, justificada por questões econômicas diretas: em geral custa mais barato importar trigo do que estimular a sua produção local. No entanto, a segunda opção pode ser viável. Todavia, tal viabilidade somente se cristalizará se um conjunto de medidas for implementado. Em primeiro lugar, a cadeia produtiva deverá se reestruturar de maneira a buscar interesses comuns para aumentar a participação do produto nacional e reduzir as importações. Ou seja, a cadeia deve operar em favor do trigo nacional e não ser utilizada por alguns elos mais ágeis para a conquista de benefícios exclusivos. Aliás, este é o grande gargalo da cadeia tritícola brasileira, pois ela não funciona na prática como uma verdadeira cadeia produtiva.

Em segundo lugar, pode-se desenvolver uma produção oriunda de agricultores com produto destinado a nichos de mercado, mediante contratos de integração. É necessário um mecanismo que garanta ao produtor uma remuneração adequada ao produto, induzindo-o a utilizar tecnologias que resultarão no aumento da produtividade e, com isso, na redução dos custos de produção. Na prática, os produtores brasileiros geralmente não produzem a qualidade que agrega mais valor e possui a maior demanda.

Na verdade, os triticultores mais tecnificados produzem o trigo de qualidade necessária, mas consideram, não sem razão, ser fundamental a correção de distorções, tais como juros elevados e prazos favoráveis na importação. Ou seja, é necessário evitar que o país importe o cereal "em condições excepcionais”, fato que caracteriza deslealdade comercial. Se isto de fato ocorresse, haveria grande impulso na busca da competitivi- 
dade e retorno a uma produção mais consistente, estimulada pelo uso de variedades não só mais produtivas, mas também melhor adequadas às necessidades dos moinhos e da indústria de alimentos. Por enquanto a competição maior pelo trigo de alta qualidade ainda está no setor de massas, porém, o avanço tecnológico já permite a produção de máquinas que, ao processarem o trigo comum, gerem uma massa de alta qualidade.

Por outro lado as necessidades de financiamento e de abastecimento dos moinhos somadas à liberdade para importar e as benesses que existem no mercado internacional - preços e condições de pagamento - têm levado a indústria moageira a dar preferência ao trigo importado, deixando em segundo plano a aquisição do produto nacional. Mesmo o trigo nacional de qualidade superior tem dificuldade de colocação no mercado devido à desvantagem representada pelo pagamento à vista ou no máximo em 30 dias. No Nordeste há ainda o encarecimento do frete do trigo nacional para abastecer aquele mercado.

Além dos preços subvencionados na origem, as vantagens dos financiamentos externos tornam a compra do trigo importado não mais uma operação de abastecimento do cereal, mas uma operação de caráter financeiro. Assim, o interesse industrial organizado dos moinhos sempre foi contrário às medidas propostas de proibição de importação com prazos e juros compatíveis com os do mercado nacional. As pressões sempre foram muito fortes para reduzir-se ainda mais as tarifas vigentes depois da abertura, enquanto que nunca se ouviu falar de uma organização de classe de triticultores, como existe nos Estados Unidos e na Europa. ${ }^{6}$

Quando se cogitou a imposição de um direito compensatório sobre o trigo importado proveniente tanto dos Estados Unidos quanto do Canadá, o interesse organizado do setor de moagem alegou que a medida redundaria apenas em mais impostos sobre produto de consumo popular e que, como o país precisaria importar o trigo destes países por falta de produto nacional, a medida seria contra o interesse dos consumidores Não se poderia prescindir do trigo canadense e norte-americano. E,

${ }^{6}$ No Rio Grande do Sul organizou-se a Fecotrigo, órgão composto pelas cooperativas tritícolas do Estado. Porém, sua atuação avançou para o conjunto de atividades mantidas pelo associado, particularmente a soja. Com a crise do cooperativismo em meados dos anos de 1990, a Fecotrigo se incorporou a Fecoagro, juntamente com outras Federações agrícolas então existentes no Estado (Fecolã, Fecovinho, Fecocarne e Fecoarroz). 
ainda mais, que ao tributar o produto de ambos países, nada mais se estaria fazendo que aumentar o preço do trigo argentino.

Este argumento era o reconhecimento de que o trigo importado com subsídio, proveniente de países formadores de preços - pelo poder de fogo que tinham em subsidiar - também afetava os preços no mercado interno: a favor dos consumidores e contra os produtores. O desequilíbrio de poder político entre as organizações agrícolas e o interesse organizado da indústria moageira era de tal ordem que os direitos compensatórios foram descartados. O trigo subsidiado instalava um conflito dentro da própria cadeia (FGV/IPEA, 1998). Este conflito de interesses, que mina o funcionamento da cadeia, dura até hoje (2005).

Um outro aspecto a destacar é a grande diferença na agregação de valor entre as diferentes partes da cadeia. Tomando-se por base o ano de 1999 (JACOBSEN, 2000), tem-se que o trigo produzido no Rio Grande do Sul, além do preço pago ao triticultor pelas cooperativas - em razão das despesas operacionais - tinha um acréscimo de 10 a 12\%, mais o custo do frete, da ordem de $\mathrm{R} \$ 1,00 / 60$ quilos. Assim, estimouse que a tonelada de trigo, pela qual o produtor recebia $\mathrm{R} \$ 216,00$ numa cooperativa (da qual era descontado o FUNRURAL de 2,2\%) custava ao moinho $\mathrm{R} \$ 238,33$ e que, acrescida do frete, se elevava a $\mathrm{R} \$ 255,00$. Essa tonelada de trigo, produzindo 760 quilos de farinha (R\$380,00) e 240 quilos de farelo ( $\mathrm{R} \$ 33,60$ ), passa a custar $\mathrm{R} \$ 413,60$ em nível de consumidor. Os 760 quilos de farinha produziriam 912 quilos de pão francês nas panificadoras que, comercializado a $\mathrm{R} \$ 2,40 /$ quilo, transformaria-se em $\mathrm{R} \$ 2.188,80$. Assim a tonelada de trigo acaba valendo 10 vezes mais junto aos panificadores finais em relação ao preço que o produtor realmente recebeu pelo produto.

Enfim, no que diz respeito ao trigo gaúcho especificamente, percebese que o setor moageiro do Brasil tem restrições ao uso geral deste produto, particularmente para panificação, embora não ocorra o mesmo quando a finalidade é a produção de biscoitos ou farinha doméstica. E os maiores responsáveis, apontados como causas de rejeição ao trigo do Rio Grande do Sul, são: a falta de homogeneização do produto (diferenças entre cargas recebidas) e a irregularidade da oferta entre as safras. Esta realidade ainda hoje (2005) é corroborada pelo setor industrial em relação a grande parte do produto gaúcho. 


\section{Referências bibliográficas}

COLLE, Célio Alberto. A Cadeia Produtiva do Trigo no Brasil: contribuição para a geração de emprego e renda. IEPE/UFRGS. Ed. UFRGS: Porto Alegre/RS, 1998. Disponível em: < http://www.ufrgs.br/pgdr/ dissertacoes/ecorural/mecorural_colle_n204.pdf > . Acesso em setembro de 2005 .

FGV/IPEA. Fatores que Afetam a Competitividade da Cadeia do Trigo. (Centro de Estudos Agrícolas), Pesquisa financiada pelo IPEA. Ed. FGV: Rio de Janeiro - RJ 1998, 39 p.

JACOBSEN, L.A. Diagnóstico Rápido da Cadeia de Trigo no Rio Grande do Sul. Ed. Embrapa : Passo Fundo/RS. 2000.

ROSSI, R.M.; NEVES, M.F. Estratégias para o trigo no Brasil. PENSA/ UNIEMP, São Paulo. Editora Atlas, 2004. 224 p.

ZYLBERSZTAJN Apud COLLE, C.A.A cadeia produtiva do trigo no Brasil: contribuição para a geração de emprego e renda. Ed.UFRGS: Porto Alegre-RS, 1998. Disponível em < http://www.ufrgs.br/pgdr/dissertacoes/ ecorural/mecorural_colle_n204.pdf > . Acesso em novembro de 2005. 